\title{
Analysis of the Dynamic Response of the Mechanism of Conventional Sucker rod Pumping Units
}

\author{
DORIN BADOIU, GEORGETA TOMA* \\ Petroleum-Gas University of Ploiesti, 39 Bucuresti Blvd., 100680, Ploiesti, Romania
}

In the kinetostatic study of the mechanism of the sucker rod pumping units, the cinematic motion parameters of the elements are considered to be known, assuming that the cranks have a constant angular velocity imposed by the operating functioning conditions of the pumping unit. The paper analyzes the dynamic response of the mechanism of these pumping units, which implies the determination of the variation of the angular acceleration of the cranks during the operating cinematic cycle. A series of results regarding the determination of the variation of the angular acceleration of the cranks during the cinematic cycle in the case of the mechanism of a C-640D305-120 pumping unit are presented. The obtained results are checked by comparing the experimental curves of variations of the acceleration at the polished rod with those obtained by simulation using a computer program developed by the authors in which the angular acceleration of the cranks was taken into consideration.

Keywords: sucker rod pumping unit, dynamic response, angular acceleration of the cranks

Establishing the variation of the angular acceleration of the cranks of the conventional sucker rod pumping units, which implies the determination of their dynamic response, is particularly important in assessing the operation of the entire pumping installation [1-3]. Obtaining high values of the angular acceleration of the cranks would reveal inadequate operation of the pumping unit, due to a poor balancing of the unit mechanism or due to the dynamics of the sucker rod string [4-7].

The paper presents the way to determine the variation on the cinematic cycle of the acceleration of the cranks of the conventional pumping units by using the synthesis parameters of the dynamic model of their mechanism. The results obtained in the case of a C-640D-305-120 pumping unit were verified by comparing the experimental curves of the variation of the acceleration of the polished rod with those obtained by simulation using a computer program developed by the authors in which the angular acceleration of the cranks was taken into consideration. Total Well Management program [11] has been used for processing the experimental records and the computer program for simulations was developed with Maple programming environment [10].

\section{Experimental part}

The experimental records have been obtained from a well serviced by a C-640D-305-120 pumping unit manufactured by Lufkin [12] and were processed with the program Total Well Management [11]. For establishing the variation of the angular acceleration of the cranks were used the records concerning the variation of the force at the polished rod and of the motor moment at the crankshaft for the strokes 90 (fig. 1) and 95 (fig. 2).

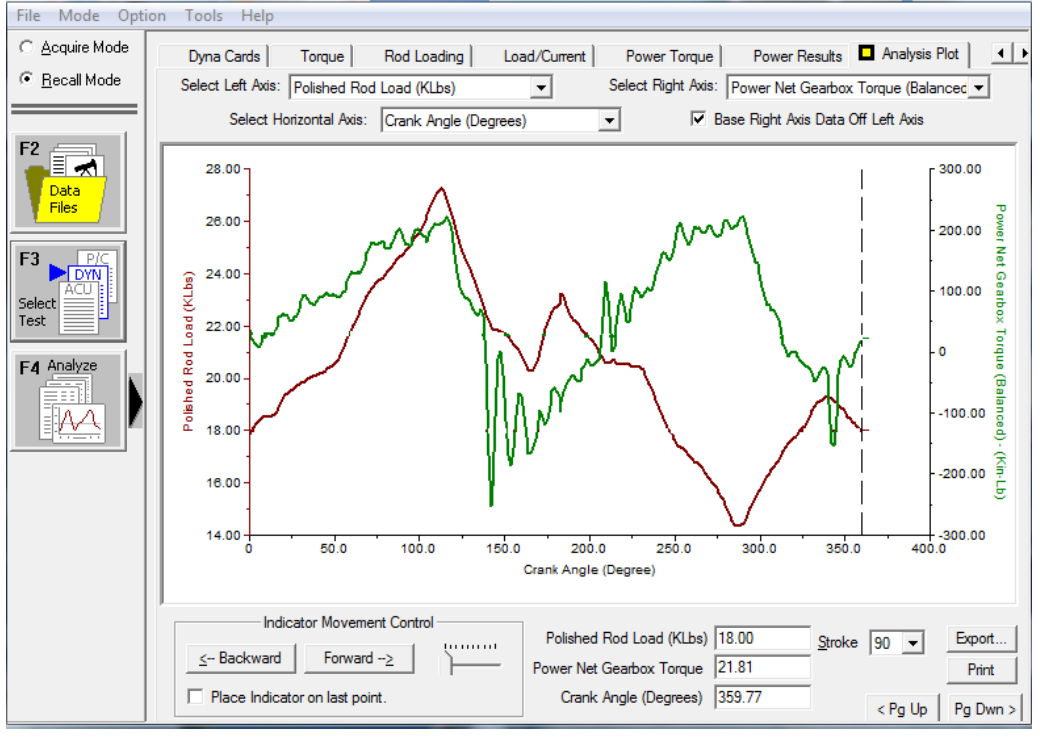

Fig. 1. The variation of the force at the polished rod and of the motor moment at the crankshaft during the stroke 90

\footnotetext{
*email: georgeta_tm@yahoo.com
} 


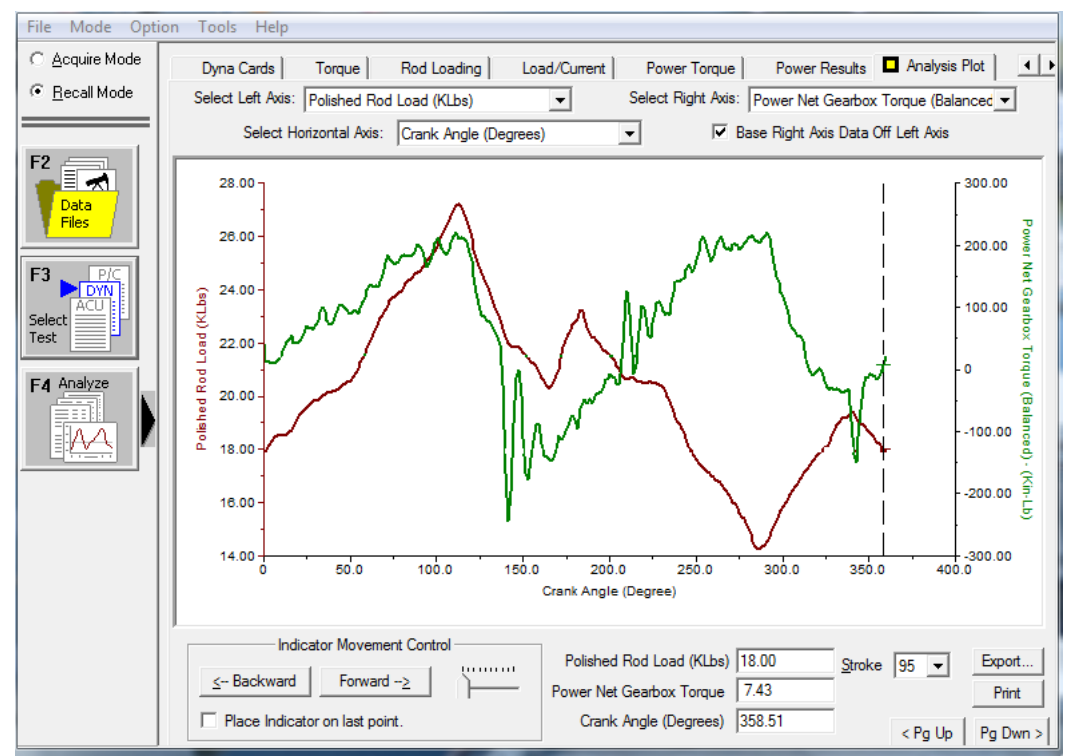

Fig. 2. The variation of the force at the polished rod and of the motor moment at the crankshaft during the stroke 95

The records concerning the variation of the acceleration at the polished rod for the two strokes 90 (fig. 3) and 95 (fig. 4) were used for verifying the simulations results obtained by taking into consideration the angular acceleration of the cranks.

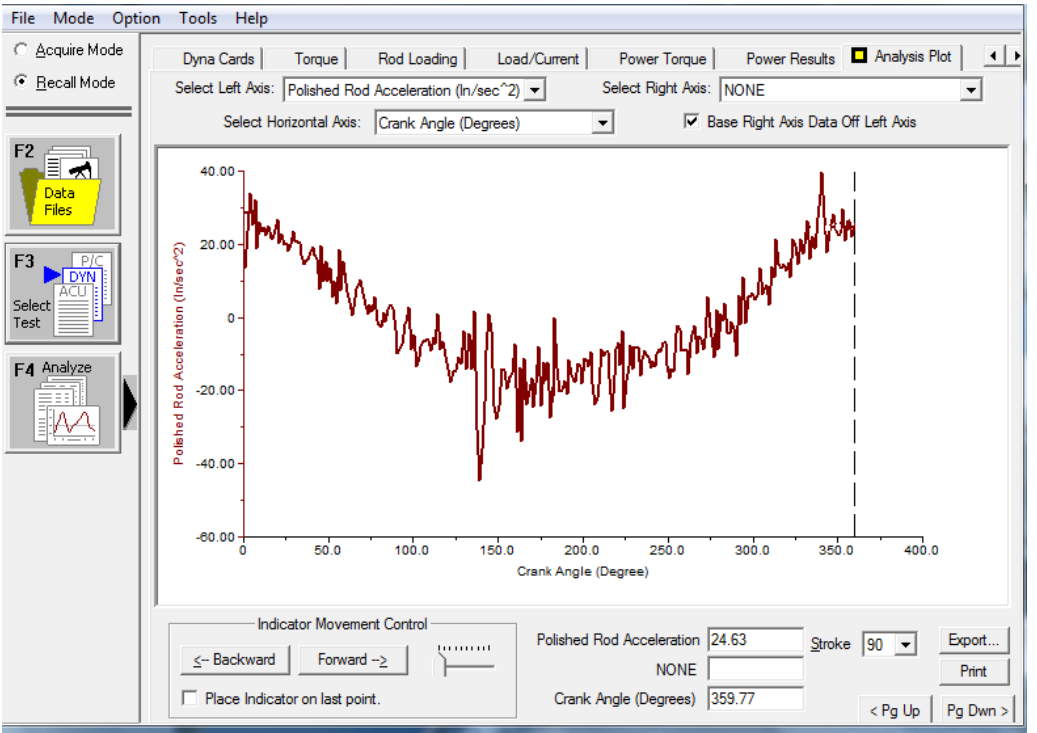

Fig. 3. The variation of the acceleration at the polished rod during the stroke 90

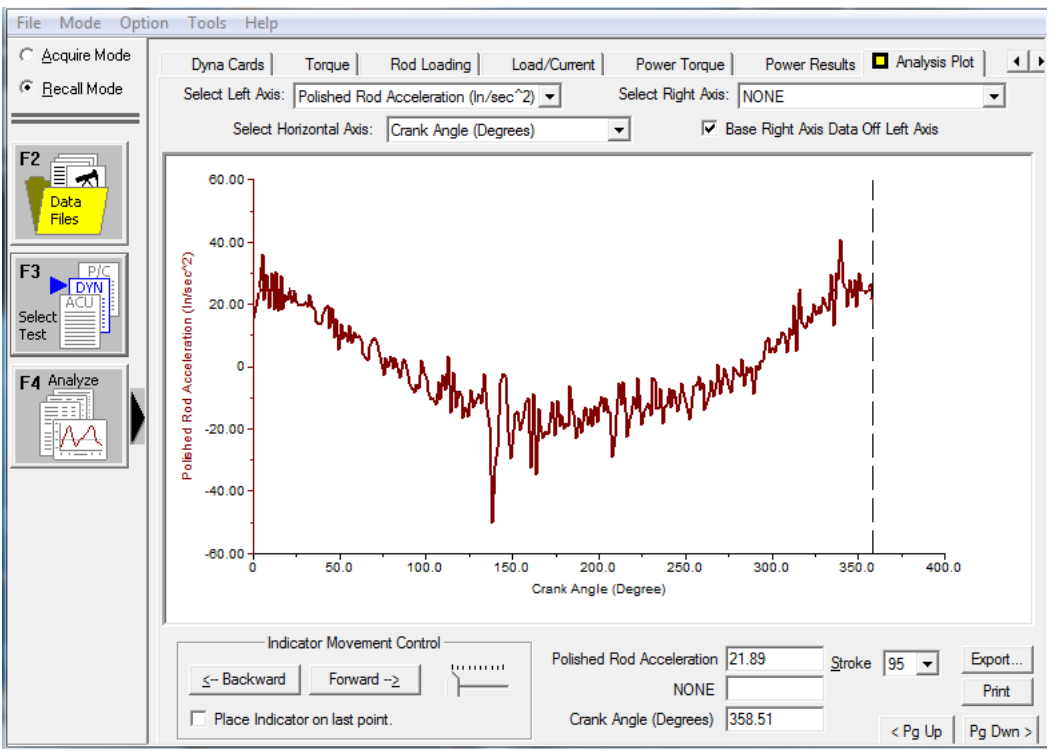

Fig. 4. The variation of the acceleration at the polished rod during the stroke 95 
Establishing the variation of the angular acceleration of the cranks during the cinematic cycle

One of the used forms for expressing the movement equation in the case of plane mechanisms is the following $[8,9]$ :

$$
\frac{1}{2} \cdot \frac{\mathrm{d} J_{r e d}}{\mathrm{~d} \varphi_{1}} \cdot \omega_{1}^{2}+J_{r e d} \cdot \frac{\mathrm{d} \omega_{1}}{\mathrm{~d} t}=M_{r e d}
$$

where: $\omega_{1}$ is the angular speed of the driving crank; $\varphi_{1}$ is the driving crank angle; $J_{\text {red }}$ is the reduced mass moment of inertia and $M_{\text {red }}$ is the reduced moment.

The way of the calculus of $J_{\text {red }}$ and $M_{\text {red }}$ in the case of the mechanism of the conventional sucker rod pumping units (fig. 1) is presented in [7].

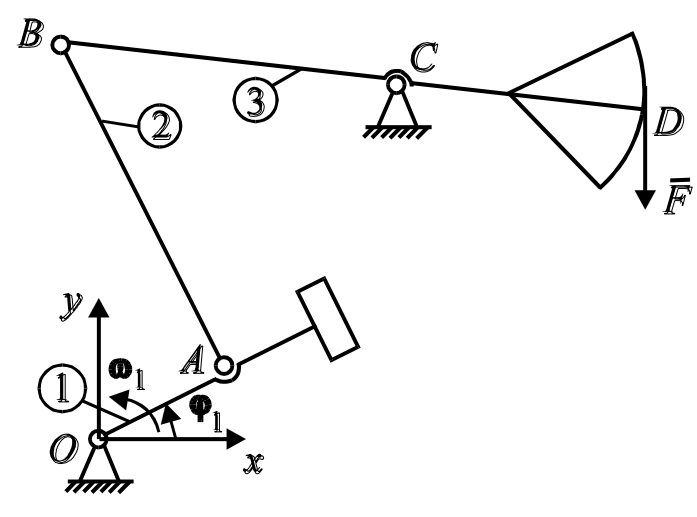

Fig. 5. The mechanism of the conventional sucker rod pumping units

In [7] has been highlighted the fact that $J_{\text {red }}$ do not depends on $\omega_{1}$ and varies very little during the cinematic cycle. So, by considering the reduced mass moment of inertia $J_{\text {red }}$ to be constant the following form of the movement equation is obtained:

$$
J_{r e d} \cdot \frac{\mathrm{d} \omega_{1}}{\mathrm{~d} t}=M_{r e d} \Leftrightarrow J_{r e d} \cdot \varepsilon_{1}=M_{r e d}
$$

where $\varepsilon_{1}$ is the angular acceleration of the cranks.

So, with relation (2) can be determined the variation during a cinematic cycle of the angular acceleration $\varepsilon_{1}$ of the cranks.

\section{Simulation results and discussions}

The simulations have been performed in the case of a C-640D-305-120 pumping unit produced by Lufkin [12] with a computer program developed by the authors using Maple programming environment [10]. The dimensions of the component elements of the mechanism of the pumping unit (fig. 5) are: $O A=30$ in. $(0.762 \mathrm{~m}) ; A B=133.5$ in. $(3.3909 \mathrm{~m}) ; B C=111.09$ in. $(2.8217 \mathrm{~m}) ; C D=155 \mathrm{in}$. $(3.937 \mathrm{~m})$. The coordinates of the point $C$ (fig. 5) are [12]: $x_{C}=111 \mathrm{in} .(2.8194 \mathrm{~m})$ and $y_{C}=138 \mathrm{in} .(3.5052 \mathrm{~m})$.

The values of the crank angles corresponding to the beginning of the upward and downward movements of the sucker rod column are $88.976^{\circ}$ and $266.982^{\circ}$, respectively.

The values of the other parameters involved in calculations are: $O A^{\prime}=51 \mathrm{in}$. $(1.2954 \mathrm{~m})$, where $A^{\prime}$ is the point where the balancing counterweights are considered to be concentrated; the total length of the cranks is 95 in. (2.413 $\mathrm{m}$ ); the mass of the spherical connecting bearing between the connecting rods and the rocker $m_{L 2}=169 \mathrm{~kg}$; the mass of the equalizer traverse $m_{t r}=580 \mathrm{~kg}$; the mass of the rocker head $m_{C B}=840 \mathrm{~kg}$; the total mass of the balancing counterweights $m_{C G}=4808 \mathrm{~kg} ; q_{1}=722 \mathrm{~kg} / \mathrm{m} ; q_{2}=34 \mathrm{~kg} / \mathrm{m} ; q_{3}=300 \mathrm{~kg} / \mathrm{m}$, where $q_{1}, q_{2}$ and $q_{3}$ are the linear masses of the cranks, connecting rods and of the rocker, respectively.

In figures 6 and 7 are presented the variation curves of the angular acceleration $\varepsilon_{1}$ of the cranks during the strokes 90 and 95, respectively. 

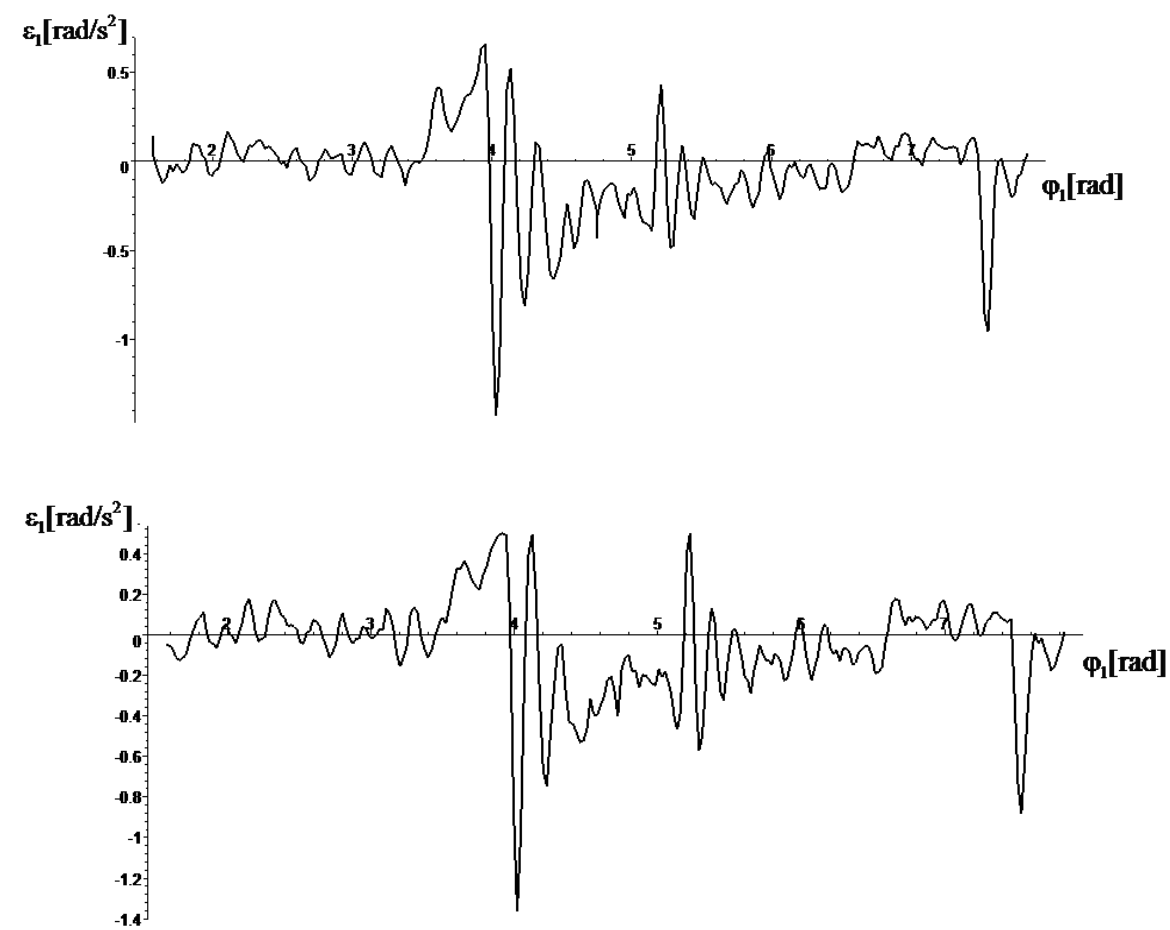

Fig. 6. The variation of the angular acceleration of the cranks during the stroke 90

The results obtained for the variation of the angular acceleration of the cranks have been verified by comparing the experimental curves of the variation of the acceleration $a_{D}$ (fig. 5) at the polished rod with those obtained by simulation when the angular acceleration of the cranks was taken into consideration. The way of calculating the acceleration at the polished rod by taking into consideration the angular acceleration of the cranks is presented in [5]. In calculus the nominal operating angular speed of the cranks has been considered to be equal to $6.6 \mathrm{rot} / \mathrm{min}$. In figures 8 and 9 are presented the variation curves of the acceleration $a_{D}$ during the strokes 90 and 95, respectively. The curves 1 correspond to the experimental records and the curves 2 have been obtained with the simulation program.

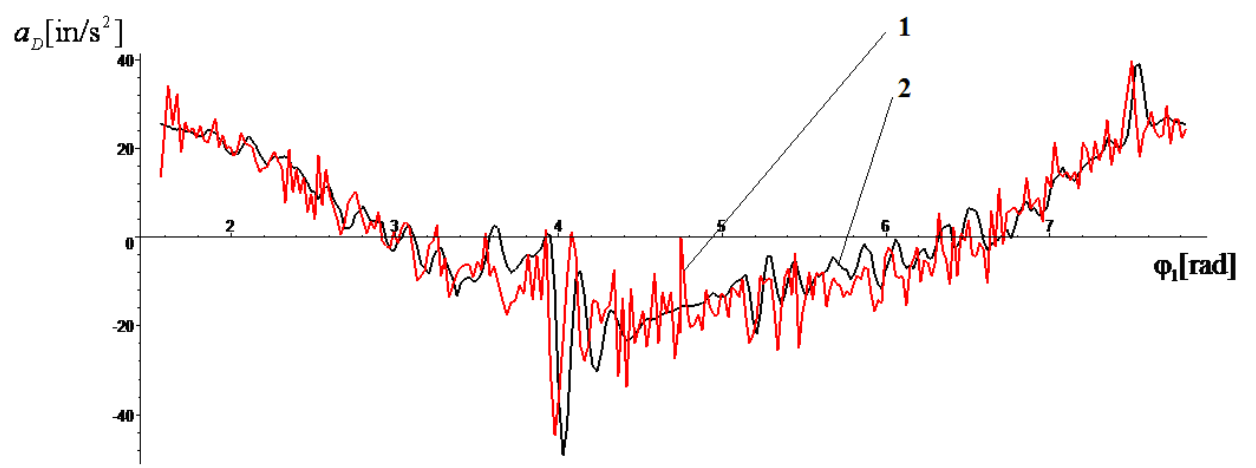

Fig. 8. The variation of the acceleration at the polished rod during the stroke 90 (experimental - curve 1 ; simulation - curve 2)

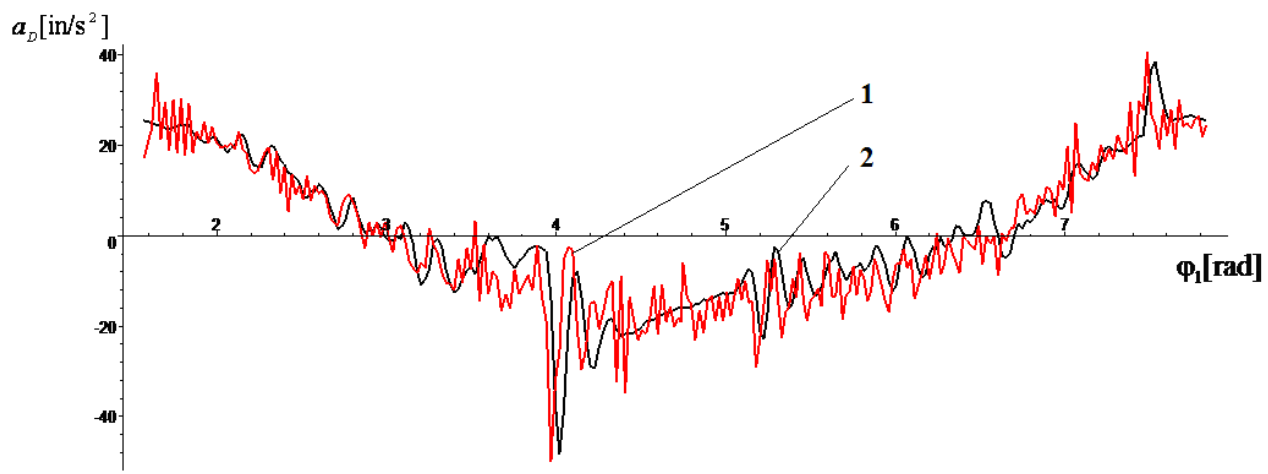

Fig. 9. The variation of the acceleration at the polished rod during the stroke 95 (experimental - curve 1 ; simulation - curve 2) 
Figures 8 and 9 highlight a very good accordance between the simulation results and the measured values of the acceleration at the polished rod, practically the curves obtained by simulation track all the small variations of the experimental values.

\section{Conclusions}

In this paper has been analyzed the way of determining the dynamic response of the mechanism of the conventional pumping units. In this respect it was presented a method for determining the variation on the cinematic cycle of the acceleration of the cranks by using the synthesis parameters of the dynamic model of the mechanism of the pumping units. The verification of the obtained results in the case of a C-640D-305-120 pumping unit has been done by comparing the experimental curves of the variation of the acceleration at the polished rod with those obtained by simulation by taking into account the angular acceleration of the cranks. It was obtained a very good accordance between the simulation and experimental results, so it can be concluded that the method presented in the paper is effective in assessing the proper functioning of conventional sucker rod pumping installations.

\section{References}

1.GIBBS, S G., Predicting the behavior of sucker-rod pumping systems, Journal of Petroleum Technology, 1963 (July), p. $769-778$

2.TOMA G., PUPAZESCU A., BADOIU D., Simulation of the Sucker Rod Column Dynamics for Different Pumping Regimes, Rev. Chim. (Bucharest), 68, no. 11, 2017, pag. 2593-2596

3.BADOIU, D., TOMA, G., Research concerning the identification of some parameters of a sucker rod pumping unit, Rev. Chim. (Bucharest), 68, no. 10, 2017, p. 2289-2292

4.BADOIU, D., TOMA, G., Research concerning the kinetostatic analysis of the mechanism of the conventional sucker rod pumping units, Rev. Chim. (Bucharest), 69, no. 7, 2018, p. 1855-1859

5.BADOIU, D., TOMA, G., Research concerning the correlations between some experimental results in the case of a sucker rod pumping installation, Rev. Chim. (Bucharest), 69, no. 11, 2018, p. 3060-3063

6.BADOIU, D., TOMA, G., Research concerning the predictive evaluation of the motor moment at the crankshaft of the conventional sucker rod pumping units, Rev. Chim. (Bucharest), 70, no. 2, 2019, p. 378-381

7.BADOIU, D., Research concerning the movement equation of the mechanism of the conventional sucker rod pumping units, Rev. Chim. (Bucharest), 70, no. 7, 2019

8.SHIGLEY, J.E., UICKER JR., J.J., Theory of machines and mechanisms, McGraw-Hill, 1981

9.BADOIU, D., Dynamic analysis of mechanisms and machines (in Romanian), Didactical and Pedagogical Publishing House, Bucharest, 2003

10.MONAGAN, M.B., GEDDES, K.O., HEAL, K.M., LABAHN, G., VORKOETTER, S.M., MCCARRON, J., DEMARCO, P., Maple Introductory Programming Guide, Maplesoft, a division of Waterloo Maple Inc., 2005

11.*** Total Well Management Help Manual, Echometer Company, Texas

12.*** Conventional Crank Balanced Pumping Units, Lufkin Oilfield Products Group, Houston, Texas

Manuscript received: 2.04 .2019 